\title{
NILAI PENDIDIKAN KARAKTER DALAM CERPEN ANAK "LAPTOP SI CALON PENULIS" SEBAGAI REFERENSI MENGHADAPI PERSAINGAN DI ERA DIGITAL
}

\author{
Rozali Jauhari Alfanani \\ Universitas Mataram \\ Pos-el: zalipasca15@gmail.com
}

\begin{abstract}
A bstrak
A rus globalisasi dianggap mampu mengubah pribadi manusia kearah yang berbeda. Perubahan pribadi manusia ini menyangkut pola asuh maupun gaya hidup yang diajarkan orang tua. $\mathrm{Hal}$ lainnya yaitu peran pendidikan karakter yang ditanamkan di lingkungan sekolah. Pola asuh orang tua dapat didefinisikan sebagai pola interaksi antara anak dengan orang tua, yang menyangkut pemenuhan kebutuhan fisik (seperti makan, minum, dan lain-lain) dan kebutuhan non-fisik (seperti perhatian, empati, kasi hayang, dan sebagainya). Pola asuh orang tua berperan penting dalam membentuk karakter anak sebagai rasa tanggung jawab mereka untuk mewujudkan pribadi anak yang mandiri, kreatif, dan inovatif. Perubahan gaya hidup yang semula manusia sebagai makhluk sosial yang saling membutuhkan berubah menjadi bersikap individualis yang tidak membutuhkan orang lain. Pola asuh dan perubahan gaya hidup mempengaruhi perubahan hidup seseorang. Oleh sebab itu, pendidikan karakter sebaiknya dikembangkan melalui pendekatan terpadu dan menyeluruh. Efektivitas pendidikan karakter tidak selalu harus dengan menambah program tersendiri, tetapi bisa melalui transformasi budaya dan kehidupan di lingkungan sekolah. Adapun metode yang digunakan dalam pendekatan ini adalah analisis teks berdasarkan nilai-nilai pendidikan karakter sehingga dapat diketahui unsur yang dapat mewujudkan pribadi yang mandiri, kreatif, dan inovatif melaluai teks sastra anak. Hal ini diharapkan dapat menyiapkan mentalitas anak dalam menghadapi persaingan global di era digital.
\end{abstract}

Kata kunci: nilai pendidikan karakter, cerpen anak, mandiri, kreatif, dan inovatif.

\begin{abstract}
The flow of globalization is considered capable of transforming thehuman person into a different direction. This personal change of human concerns the pattern of upbringing and lifestyletaught by parents. There is also the role of character education implemented in theschool environment. Parenting patterns can bedefined as patterns of interaction between children and parents, involves the fulfillment of physical needs (such as eating, drinking, etc.) and non-physical needs (such as attention, empathy, compassion, etc.). Parenting patterns play an important role in shaping the character of children as a sense of their responsibility to realize the personal child self-reliant, creative, and innovative. Changes in lifestyle that originally human as social beings that need each other transformed into an individual ist attitudethat does not need other people. Parenting and lifestyle changes affect a person's lifechanges. Ther efore, character education should be developed through a comprehen siveand integrated approach. The effectiveness of character education does not al ways have to add to its own program, but it can bethrough the transformation of culture and life in school environment. The method used in this approach is text analysis based on the values of character education so that it can beknown elements that can real izean independent, creative, and innovativeperson through theliterary text of the child. It is expected to preparethementality of children in theface of global competition in the digital age.
\end{abstract}

Keyw ords: value of character education, life, children, independent, creative, and innovative. 


\section{PEN DAHULUAN}

Perkembangan IImu Pengetahuan dan Teknologi (IPTEK) semakin pesat di tengah persaingan global, tetapi moralitas bangsa seolah semakin terpuruk. Salah satu contoh perkembangan IPTEK yaitu meningkatnya pemakaian gawai di kalangan masyarakat, mulai dari anak-anak hingga orang dewasa. Bahkan, para orang tua lebih senang dan bangga jika anaknya terampil menggunakan gawai, tetapi mereka abai dengan berbagai dampak negatif dari penggunaannya yang berlebihan.

Seperti halnya manusia dewasa, anak pun membutuhkan informasi tentang dunia yang terjadi di sekelilingnya yang dapat menjadi alat, media, dan wadah pendidikannya. Dalam hal ini, sastra anak dapat dijakan alternatif oleh para orang tua untuk mendidik anaknya. Sastra anak adalah buku-buku bacaan yang sengaja ditulis untuk dikonsumsikan kepada anak, buku-buku yang isi kandungannya sesuai dengan minat dan dunia anak, sesuai dengan tingkat perkembangan emosional dan intelektual anak, dan buku-buku yang karenanya dapat memuaskan anak (Nurgiyantoro, 2013:8).

Berkaitan dengan hal tersebut, salah satu strategi membermaknakan nilai pendidikan karakter pada anak yaitu melalui kegiatan apresiasi sastra, khususnya sastra anak. Cerita dalam karya sastra anak yang disajikan dengan menarik berpotensi dapat mengembangkan kognisi dan daya apresiasi anak. A presiasi ce rita anak memiliki sumbangan bagi perkembangan kepribadian anak dalam proses menuju kedewasaan sebagai manusia yang mempunyai jati diri atau karakter.

Dalam hal ini, pendidikan karakter yang lebih menekankan nilai etis-spiritual bukanlah hal yang baru. Secara mendasar, pendidikan karakter memuat pada pengajaran inti berbasis pada model pembelajaran mengalami (experience). Inti pembelajarannya adalah mengajarkan kepada anak tentang adanya suatu kekuatan lebih tinggi yang mengatur alam dan isi jagad raya ini. A jarkan sesuatu pada anak bahwa sebagai manusia senantiasa tidak lepas dari kekuatan tersebut untuk mampu menciptakan dan merasakan hidup yang lebih baik. A pabila anak sudah meyakini ada Yang Mahakuasa, maka kehidupannya tidak dirasakan sebagai pengetahuan kognitif saja.

\section{TEORI DAN METODE}

Pengembangan karakter pada anak meIalui apresiasi terhadap sastra anak, khususnya cerita anak, memberikan efek atau hasil berupa berbagai sikap dan sifat yang positif dalam kehidupan si anak. Hal tersebut menjadi nilai tambah bagi si anak dalam menjalani kehidupannya secara berkelanjutan di tengah masyarakat. Adapun sikap dan sifat positif tersebut yaitu mandiri, kreatif dan inovatif.

\section{Mandiri}

Mandiri adalah suatu sikap dan perilaku yang tidak mudah tergantung pada orang lain dalam menyelesaikan tugas-tugas (Kurniawan, 2013:143). Dengan melakukan kegiatan apre siasi sastra, anak diharapkan mampu menjadi pribadi mandiri yang tidak terlalu menggantungkan diri pada orang lain. Kegiatan apresiasi diharapkan dapat merangsang anak-anak dalam mengerjakan dan melaksanakan tugas tanpa tergantung pada orang lain. Anak bisa menyelesaikan permasalahan secara bijak, menjadi pribadi yang tangguh, dan tidak mudah menyerah.

\section{Kreatif}

Sementara itu, kreatif adalah suatu kemampuan umum untuk menciptakan suatu hal yang baru, sebagai kemampuan untuk memberikan gagasan-gagasan baru yang dapat diterapkan dalam pemecahan masalah, atau sebagai kemampuan untuk melihat hubunganhubungan baru antara unsur-unsur yang sudah ada sebelumnya (Kurniawan, 2013:140). Kreatif berarti dapat meningkatkan kualitas diri dengan meningkatkan kreativitas.

3. Inovatif

Kemudian, inovatif adalah cara berpikir dan melakukan sesuatu secara kenyataan atau 
logika untuk menghasilkan cara atau hasil baru dan termutakhir dari apa yang telah dimiliki. Mampu menciptakan sesuatu yang unik dan juga berbeda agar mempunyai nilai jual yang tinggi juga merupakan ciri anak yang inovatif. Inovatif juga berarti berorientasi pada penemuan baru dengan melihat kebutuhan masyarakat dan pandai membaca peluang.

Dalam menghadapi persaingan era digital yang semakin kompleks, kreativitas dan inovasi menjadi hal yang utama dalam menciptakan keunggulan kompetitif. Dunia global memerlukan sumber daya manusia yang kreatif dan inovatif. Misalnya, untuk menjadi seorang wirausaha, sikap mental yang tangguh ditunjang dengan kompetensi yang tinggi dan penuh perhitungan sangat membantu keberhasilan dalam berwirausaha.

4. Karakter dan pendidikan karakter

Istilah karakter dapat dimaknai sebagai kualitas individu yang menjadi ciri seseorang atau kelompok dalam masyarakat. Dalam konteks pendidikan, karakter merupakan nilai-nilai yang unik. Pendidikan karakter dapat dimaknai sebagai pendidikan nilai, pendidikan budi pekerti, pendidikan moral, pendidikan watak, yang bertujuan untuk mengembangkan kemampuan siswa agar dapat memberi keputusan baik-buruk, memelihara apa yang baik, dan mewujudkan kebaikan itu dalam kehidupan sehari-hari dengan sepenuh hati (Rencana A ksi Nasional Pendidikan Karakter, Kemendiknas, 2010-2014). Dalam hal ini, peran pembeIajaran bahasa Indonesia diharapkan dapat membantu siswa mengenal dirinya, budaya, bernegosiasi dalam kehiduan bermasyarakat, dan menggunakan kemampuan analitis dan imajinatif yang dalam di dalam diri siswa. $\mathrm{Hal}$ itu berdasarkan salah satu tujuan mata pelajaran bahasa Indonesia yaitu agar peserta didik memiliki kemampuan menikmati dan memanfaatkan karya sastra untuk memperluas wawasan, memperluas budi pekerti, serta me ningkatkan pengetahuan dan kemampuan berbahasa.
5. Nilai

Nilai merupakan daya dorong yang melandasi sikap, perilaku dan nilai-nilai yang terpatri dalam diri kita melalui pengalaman, pendidikan, dan pengorbanan, menjadi nilai intrinsik yang melandasi sikap dan berperilaku kita. Kenyataannya, pendidikan karakter di sekolah selama ini baru mencapai pengenalan norma atau nilai-nilai, belum pada internalisasi dan implementasi nilai dalam kehidupan seharihari.

Adapun prinsip-prinsip pengembangan nilai pendidikan karaker melalui pembelajaran bahasa Indonesia adalah sebagai berikut.

1. Berkelanjutan, berarti proses implementasi dan pengembangan nilai karakter merupakan sebuah proses panjang dan berkelanjutan, mulai dari peserta didik masuk hingga selesai dari suatu satuan pendidikan, dari lingkungan keluarga, sekolah, berlanjut ke lingkungan masyarakat.

2. Menyeluruh, berarti proses implementasi dan pengembangan pendidikan karakter tidak hanya melalui pembelajaran di kelas, tetapi juga melalui ekstrakurikuler, pengembangan budaya sekolah, dan peningkatan peran serta masyarakat.

3. Nilai tidak hanya diajarkan tapi dipraktikan melalui peneladanan dan pembiasaan.

4. Proses penanaman nilai melalui pembelajaran dilakukan secara partisipatif, aktif dan menyenangkan.

5. Latihan dan pembiasaan.

6. Keteladanan

7. Keterkaitan (Kemendikbud, 2012:9 12)

Selain itu, tujuan inti dari pendidikan karakter yaitu, 1) membentuk bangsa yang tangguh; 2) kompetitif; 3) berakhlak mulia; 4) bermoral; 5) bertoleran; 6) bergotong royong; 7) berjiwa patriotik; 8) berkembang dinamis; dan 
9) berorientasi ilmu pengetahuanan teknologi. memperkuat dan membangun perilaku bangsa Pendidikan karakter juga berfungsi untuk 1) yang multikultur; dan 3) meningkatkan menggambarkan potensi dasar agar berhati peradaban bangsa yang kompetitif dalam baik, berpikiran baik, dan berperilaku baik; 2) pergaulan dunia.

\begin{tabular}{|c|c|}
\hline $\begin{array}{l}18 \text { Nilai Pendidikan } \\
\text { Karakter } \\
\text { yang } \\
\text { Dikembangkan } \\
\end{array}$ & Deskripsi Prilaku \\
\hline \multicolumn{2}{|c|}{ 1. N ilai karakter dalam hubungannya dengan Tuhan Yang Maha Esa } \\
\hline Religius & $\begin{array}{l}\text { Berkaitan dengan nilai ini, pikiran, perkataan, dan tindakan } \\
\text { seseorang yang diupayakan selalu berdasarkan pada nilai-nilai } \\
\text { ketuhanan dan/ atau ajaran agamanya. }\end{array}$ \\
\hline \multicolumn{2}{|c|}{ 2. N ilai karakter dalam hubungannya dengan diri sendiri } \\
\hline Jujur & $\begin{array}{l}\text { Merupakan perilaku yang didasarkan pada upaya menjadikan } \\
\text { dirinya sebagai orang yang selalu dapat dipercaya dalam } \\
\text { perkataan, tindakan, dan pekerjaan, baik terhadap diri dan pihak } \\
\text { lain. }\end{array}$ \\
\hline Bertanggung jawab & $\begin{array}{l}\text { Merupakan sikap dan perilaku seseorang untuk melakanakan } \\
\text { tugas dan kewajibannya sebagaimana yang seharusnya dia } \\
\text { lakukan, terhadap diri sendiri, masyarakat, lingkungan (alam, } \\
\text { sosial dan budaya), negara dan Tuhan YME. }\end{array}$ \\
\hline Bargaya hidup sehat & $\begin{array}{l}\text { Segala upaya untuk menerapkan kebiasaan yang baik dalam } \\
\text { menciptakan hidup yang sehat dan menghindarkan kebiasaan } \\
\text { buruk yang dapat mengganggu kesehatan. }\end{array}$ \\
\hline Disiplin & $\begin{array}{l}\text { Merupakan suatu tindakan yang menunjukkan perilaku tertib } \\
\text { dan patuh pada berbagai ketentuan dan peraturan. }\end{array}$ \\
\hline Kerja keras & $\begin{array}{l}\text { Merupakan suatu perilaku yang menunjukkan upaya sungguh- } \\
\text { sungguh dalam mengatasi berbagai hambatan guna } \\
\text { menyelesaikan tugas (belajar/ pekerjaan) dengan sebaik-baiknya. }\end{array}$ \\
\hline Percaya diri & $\begin{array}{l}\text { Merupakan sikap yakin akan kemampuan diri sendiri terhadap } \\
\text { pemenuhan ketercapaiannya setiap keinginan dan harapannya. }\end{array}$ \\
\hline Berjiwa wirausaha & $\begin{array}{l}\text { Sikap dan perilaku yang mandiri dan pandai atau berbakat } \\
\text { mengenali produk baru, menentukan cara produksi baru, } \\
\text { menyusun operasi untuk pengadaan produk baru, } \\
\text { memasarkannya, serta mengatur permodalan operasinya. }\end{array}$ \\
\hline $\begin{array}{l}\text { Berpikir logis, kritis, } \\
\text { kreatif, dan inovatif }\end{array}$ & $\begin{array}{l}\text { Berpikir dan melakukan sesuatu secara kenyataan atau logika } \\
\text { untuk menghasilkan cara atau hasil baru dan termutakhir dari } \\
\text { apa yang telah dimiliki. }\end{array}$ \\
\hline Mandiri & $\begin{array}{l}\text { Suatu sikap dan perilaku yang tidak mudah tergantung pada } \\
\text { orang lain dalam menyelesaikan tugas-tugas. }\end{array}$ \\
\hline
\end{tabular}




\begin{tabular}{|c|c|}
\hline Ingin tahu & $\begin{array}{l}\text { Sikap dan tindakan yang selalu berupaya untuk mengetahui lebih } \\
\text { mendalam dan meluas dari apa yang dipelajarinya, dilihat, dan } \\
\text { didengar. }\end{array}$ \\
\hline Cinta ilmu & $\begin{array}{l}\text { Cara berpikir, bersikap, dan berbuat yang menunjukkan } \\
\text { kesetiaan, kepedulian, dan penghargaan yang tinggi terhadap } \\
\text { pengetahuan. }\end{array}$ \\
\hline \multicolumn{2}{|c|}{ 3. N ilai karakter dalam hubungannya dengan sesama } \\
\hline $\begin{array}{lll}\text { Sadar akan hak } & \text { dan } \\
\text { kewajiban diri } & \text { dan } \\
\text { orang lain. } & & \end{array}$ & $\begin{array}{l}\text { Sikap tahu dan mengerti serta melaksnakan apa yang menjadi } \\
\text { milik/ hak diri sendiri dan orang lain serta tugas/ kewajiban diri } \\
\text { sendiri serta orang lain. }\end{array}$ \\
\hline $\begin{array}{l}\text { Patuh pada aturan- } \\
\text { aturan sosial. }\end{array}$ & $\begin{array}{l}\text { Sikap menurut dan taat terhadap aturan-aturan berkenaan } \\
\text { dengan masyarakat dan kepentingan umum. }\end{array}$ \\
\hline $\begin{array}{l}\text { Menghargai karya dan } \\
\text { prestasi orang lain. }\end{array}$ & $\begin{array}{l}\text { Sikap dan tindakan yang mendorong dirinya untuk } \\
\text { menghasilkan sesuatu yang berguna bagi masyarakat, mengakui } \\
\text { dan menghormati keberhasilan orang lain. }\end{array}$ \\
\hline Santun & $\begin{array}{l}\text { Sifat yang halus dan baik, dari sudut pandang tata bahasa } \\
\text { maupun tata perilakunya, ke semua orang. }\end{array}$ \\
\hline Demokratis & $\begin{array}{l}\text { Cara berpikir, bersikap, dan bertindak yang menilai sama hak } \\
\text { dan kewajiban dirinya dan orang lain. }\end{array}$ \\
\hline \multicolumn{2}{|c|}{ 4. Nilai karakter dalam hubungannya dengan lingkungan dan bangsa } \\
\hline Nilai kebangsaan & $\begin{array}{l}\text { Cara berpikir, bertindak, dan wawasan yang menempatkan } \\
\text { kepentingan bangsa dan negara di atas kepentingan diri dan } \\
\text { kelompoknya. }\end{array}$ \\
\hline Nasionalis & $\begin{array}{l}\text { Cara berpikir, bersikap, dan berbuat yang menunjukkan } \\
\text { kesetiaan, kepedulian, dan penghargaan yang tinggi terhadap } \\
\text { bahasa, lingkungan fisik, sosial, budaya, ekonomi, dan politik } \\
\text { bangsanya. }\end{array}$ \\
\hline $\begin{array}{l}\text { Menghargai } \\
\text { keberagaman }\end{array}$ & $\begin{array}{l}\text { Sikap memberi respek/ hormat terhadap berbagai macam hal baik } \\
\text { yang berbentuk fisik, sifat, adat, budaya, suku, dan agama. }\end{array}$ \\
\hline
\end{tabular}

Berbagai karakter tersebut membutuhkan media yang tepat, salah satunya yaitu dengan mendongeng atau membaca cerpen anak untuk merangsang perkembangan kemampuan berpikir secara sistematis. Berdasarkan perkembangan kognitif, menurut Piaget, pada periode III anak-anak mengembangkan kemampuan berpikir sistematis, tapi hanya ketika mereka dapat mengacu pada objek-objek dan aktivitasaktivitas konkret.
Selanjutnya, metode yang digunakan dalam tulisan ini untuk menganalisis cerpen anak yang berjudul "Laptop Si Calon Penulis", yaitu deskriptif kualitatif. Cerpen tersebut akan dianalis berdasakan nilai pendidikan karakter yang terdapat di dalamnya. Cepen anak ini berisi mengenai perjuangan seorang anak dalam mewujudkan impian dan terus berjuang mengembangkan bakatnya untuk mengubah hidupnya. 


\section{HASIL DAN PEMBAHASAN}

\section{Sinopsis Laptop Si Calon Penulis}

Mengisahkan seorang anak yang masih duduk di bangku sekolah dasar, bernama Najwa Khairunnisa. Najwa berasal dari keluarga yang sederhana, ayahnya bekerja se bagai pegawai kantoran biasa. Najwa mempunyai sahabat bernama Gina. Gina berasal dari keluarga kaya, tapi baik hati dan selalu menolong Najwa dalam kesulitan. Gina selalu memberikan semanagat pada Najwa untuk selalu berkarya. Najwa bercita-cita menjadi seorang penulis terkenal. Dia terpukau dengan karya-karya penulis terkenal, selain itu juga dari menulis bisa menghasilkan uang.

Najwa akan mengikuti lomba menulis yang dikirimkan lewat pos atau melalui internet. Waktu pengumpulan cerita untuk lombanya tinggal 2 minggu lagi. Sedangkan komputer yang ada di rumahnya selalu digunakan oleh ayah untuk mengerjakan pekerjaan kantor yang belum terselesaikan. Gina menawarkan bantuan pada Najwa, untuk memakai laptop pribadinya. Namun Najwa menolak karena dia terlalu sering menggunakan laptop Gina. Dia memilih mengerjakan di warnet dalam menye lesaikan cerita yang akan dilombakan.

Najwa ingin sekali mempunyai laptop. Jika ia memenangkan lomba menulis ini, rencananya uang yang ia dapatkan akan dipergunakan untuk membeli laptop. N ajwa selalu menyisihkan uang jajannya untuk ditabung. Kalau hanya mengandalkan uang yang disisihkannya setiap hari dari uang sakunya rasanya mustahil. Dia memikirkan cara agar cepat mendapatkan uang. Dia memutuskan untuk berjualan. Najwa membuat tempat pensil dan dompet, ternyata hasilnya pun lumayan.

Pengumuman pemenang lomba diumumkan melalui internet. Najwa merasa kecewa karena namanya tidak berada di urutan juara 1, 2, dan 3 lomba menulis cerpen, ia masuk ke dalam 5 besar pemenang hiburan. Hadiah uang sebesar Rp500.000,00 dimasukkan ke dalam rekeningnya untuk membeli laptop.

Beberapa bulan kemudian, uang Najwa sudah terkumpul lebih dari Rp2.000.000,00. Itu sudah cukup untuk membeli sebuah laptop yang sedang diskon. Walaupun kurang bagus, yang penting bisa dipakai. Seminggu kemudian, ia mendapat surat dari redaksi majalah anak-anak. Ternyata karyanya kemarin diterima dan akan dimuat. la diminta membuat cerpen lagi untuk majalah itu. la juga mulai menulis novel dan mengirimkan ke suatu penerbit. Sekarang, ia sudah membuat 4 judul buku. Juga sudah banyak yang mengenalnya. Akhirnya impian Najwa terwujud, ia mempunyai peluang untuk menjadi penulisterkenal di Indonesia. 
Tabel 1. Analis N ilai Pendidikan Karakter dalam Cerpen Anak “Laptop Si Calon Penulis" Karya N ur Alfia Rahmah

\begin{tabular}{|c|c|c|c|}
\hline No & $\begin{array}{c}\text { Nilai Pendidikan } \\
\text { Karakter }\end{array}$ & Teks & Analisis \\
\hline 1 & $\begin{array}{l}\text { Nilai Karakter dalam } \\
\text { hubungannya dengan } \\
\text { Tuhan Yang M aha Esa } \\
\text { (Religius) }\end{array}$ & $\begin{array}{l}\text { Allahu Akbar, allahu } \\
\text { A kbar ... Azan magrib } \\
\text { berkumandang. Ah, tak } \\
\text { terasa, hari sudah } \\
\text { hampir malam. Setelah } \\
\text { menyimpan kerangka- } \\
\text { ku ke dalam flasdisk, } \\
\text { aku segera pulang. }\end{array}$ & $\begin{array}{l}\text { Kalimat di samping } \\
\text { mencerminkan bahwa ketika } \\
\text { suara azan berkumandang } \mathrm{N} \text { ajwa } \\
\text { akan bergegas pulang. Hal ini } \\
\text { menandakan keimanan dan } \\
\text { ketakwaannya terhadap Tuhan } \\
\text { Yang Maha Esa. }\end{array}$ \\
\hline 2 & Mandiri & $\begin{array}{l}\text { “Tidak usah! Najwa } \\
\text { tidak enak jika harus } \\
\text { memakai laptopmu } \\
\text { terus,” tolakku lembut. }\end{array}$ & $\begin{array}{l}\text { Kalimat di samping } \\
\text { mencerminkan bahwa tokoh } \\
\text { tidak mau merepotkan orang lain } \\
\text { untuk memenuhi kebutuhannya. } \\
\text { Tokoh berusaha memecahkan } \\
\text { persoalannya sendiri tanpa } \\
\text { tergantung kepada orang lain. }\end{array}$ \\
\hline 3 & Kerja keras & $\begin{array}{l}\text { Najwa mulai } \\
\text { mengumpulkan uang. } \\
\text { Sehari, dua hari, } \\
\text { seminggu, akhirnya } \\
\text { berlalu. Najwa sudah } \\
\text { menyisihkan uang jajan } \\
\text { sehari-hari. }\end{array}$ & $\begin{array}{l}\text { Kalimat di samping, merupakan } \\
\text { upaya sungguh-sungguh yang } \\
\text { dilakukan Najwa untuk } \\
\text { mengumpulkan uang. Ia rela } \\
\text { menyisihkan uang jajannya untuk } \\
\text { ditabung. Perilaku menyisihkan } \\
\text { uang jajan merupakan wujud } \\
\text { kerja keras yang dilakukan untuk } \\
\text { memenuhi keinginannya. }\end{array}$ \\
\hline 4 & Berjiwa wirausaha & $\begin{array}{l}\text { “Kucoba dulu segini, } \\
\text { mungkin bisa laku. } \\
\text { N ajwa juga akan } \\
\text { menerima pesanan, } \\
\text { ucapku gembira. }\end{array}$ & $\begin{array}{l}\text { Perilaku yang ditunjukkan Najwa } \\
\text { dalam kalimat di samping } \\
\text { merupakan perilaku kemandirian } \\
\text { dalam berwirausaha memasarkan } \\
\text { sebuah produk. }\end{array}$ \\
\hline 5 & Berpikir logis & $\begin{array}{l}\text { Najwa memang bercita- } \\
\text { cita menjadi seorang } \\
\text { penulis terkenal sejak } \\
\text { kecil. Najwa begitu } \\
\text { terpukau dengan } \\
\text { karya-karya penulis } \\
\text { terkenal itu. Najwa } \\
\text { dengar jika jadi penulis, } \\
\text { bisa menghasil-kan } \\
\text { uang dari karyanya. } \\
\text { Najwa ingin uang itu } \\
\text { nanti untuk membantu } \\
\text { keluargaku. }\end{array}$ & $\begin{array}{l}\text { Tokoh Najwa bercita-cita ingin } \\
\text { menjadi penulis dengan bakat } \\
\text { yang ada dalam dirinya. Ia } \\
\text { berpikiran bahwa dengan } \\
\text { menjadi penulis ia akan } \\
\text { menghasilkan banyak uang, } \\
\text { sehingga dapat membantu } \\
\text { keuangan keluarganya. }\end{array}$ \\
\hline
\end{tabular}




\begin{tabular}{|c|c|c|c|}
\hline 6 & $\begin{array}{l}\text { Sadar akan hak dan } \\
\text { kewajiban diri dan } \\
\text { orang lain }\end{array}$ & $\begin{array}{l}\text { "Bagaimana kalau } \\
\text { pakai laptopku saja?" } \\
\text { tawar Gina yang } \\
\text { memang mempunyai } \\
\text { laptop pribadi. }\end{array}$ & $\begin{array}{l}\text { Gina menyadari akan } \\
\text { kewajibannya untuk membantu } \\
\text { teman yang sedang dalam } \\
\text { kesulitan. Gina berusaha } \\
\text { menawarkan laptopnya kepada } \\
\text { Najwa. }\end{array}$ \\
\hline 7 & $\begin{array}{l}\text { Menghargai karya dan } \\
\text { prestasi orang lain }\end{array}$ & $\begin{array}{l}\text { "Tapi, kamu sebaiknya } \\
\text { mengikuti lomba itu! } \\
\text { Kalau kamu menang, } \\
\text { ‘kan ada hadiah } \\
\text { uangnya juga. } \\
\text { Lumayan Iho, } \\
\text { hadiahnya, } 5 \text { juta } \\
\text { rupiah! Lalu, karyamu } \\
\text { juga akan dimuat di } \\
\text { sebuah buku anak- } \\
\text { anak" bujuk Gina. }\end{array}$ & $\begin{array}{l}\text { Kalimat di samping } \\
\text { menunjukkan, betapa gigihnya } \\
\text { Gina membujuk Najwa untuk } \\
\text { mengikuti lomba menulis cerpen. } \\
\text { Gina mempunyai keyakinan } \\
\text { bahwa tulisannya layak untuk } \\
\text { dimuat di sebuah buku. Perilaku } \\
\text { ini menunjukkan sikap } \\
\text { menghargai karya orang lain. }\end{array}$ \\
\hline 8 & Santun & $\begin{array}{l}\text { Komputer di rumahku } \\
\text { memang ada satu, dan } \\
\text { sering dipakai untuk } \\
\text { keperluan kerja ayah. } \\
\text { A ku juga hanya bisa } \\
\text { memakainya saat } \\
\text { ayahku tidak sibuk. }\end{array}$ & $\begin{array}{l}\text { Sikap santun berdasarkan } \\
\text { perilaku dengan kesabarannya } \\
\text { menggunakan komputer jika } \\
\text { ayahnya tidak sibuk merupakan } \\
\text { wujud santun tokoh Najwa. }\end{array}$ \\
\hline 9 & Rela berkorban & $\begin{array}{l}\text { “Biaya administrasi } \\
\text { Gina kurang Rp. } \\
2.000 .000 ! \text { A yah lupa } \\
\text { membawa uang lagi. } \\
\text { Kalau tidak segera } \\
\text { dibayar, Gina akan } \\
\text { dikeluarkan!” serunya. } \\
\text { A ku menawarkan uang } \\
\text { buat membeli laptopku } \\
\text { untuk dipakai dulu } \\
\text { membayar biaya } \\
\text { administrasi Gina. A ku } \\
\text { ingin sekali menolong } \\
\text { sahabat yang telah } \\
\text { banyak menolongku. }\end{array}$ & $\begin{array}{l}\text { Tokoh Najwa rela mengorbankan } \\
\text { uang tabungannya untuk } \\
\text { membantu Gina. Wujud perilaku } \\
\text { rela berkorban yang lebih } \\
\text { mementingkan kepentingan } \\
\text { orang lain daripada diri sendiri. }\end{array}$ \\
\hline
\end{tabular}




\section{PEN UTUP}

Pendidikan karakter merupakan suatu kebutuhan mendasar dalam proses berbangsa. Bangsa yang besar adalah bangsa yang memiliki karakter dan jati diri yang kuat untuk menghadapi persaingan global. Penddikan karakter di negara kita belum berjalan optimal. Hal ini disebabkan oleh dua aspek yaitu pola asuh maupun gaya hidup yang diajarkan orang tua, juga peran pendidikan karakter yang ditanamkan di lingkungan sekolah. Hal ini harus berjalan secara beriringan baik di lingkungan keluarga maupun di lingkungan sekolah.

Pelaksanaan pendidikan karakter perlu direvitalisasi sehingga mampu mendukung terbentuknya karakter positif siswa sebagaimana yang diharapkan dalam tujuan pendidikan nasional. Peran keluarga dalam pembentukkan karakter anak yang menyangkut pola asuh dan gaya hidup sama pentingnya. Penanaman gemar membaca perlu diterapkan sedini mungkin pada anak, sehingga dengan membaca cerpen diharapkan mampu menanamkan nilai pendidikan karakter dalam diri anak. Bukan hanya sekedar memahami nilai-nilai moral saja tetapi anak bisa menerapkannya dalam kehidupan sehari-hari.

Pada usia 7-11 tahun anak sudah memiliki kemampuan untuk menguasai keterampilam berbahasa seperti menyimak, berbicara, membaca, dan menulis. Keterampilan tersebut merupakan bekal dalam memahami sastra. Bahkan, pada usia ini, dapat dikatakan jika anak-anak lebih menyukai dunia sastra dibandingkan dengan berhitung. Hal ini terjadi karena sastra anak disesuaikan berdasarkan pengetahuan dan pengalaman anak. Perkembangan intelektual dan emosional anak ditentukan oleh karakter kepribadian dan lingkungan. Ini berarti bahwa jati diri anak yang sudah mempunyai karakteristik pengetahuannya sendiri, juga dipengaruhi oleh pendidikan di sekolah, keluarga, dan lingkungan sosialnya.

\section{DAFTAR PUSTAKA}

Ampera, Taufik. 2010. Pengajaran Sastra Teknik M engajar Sastra A nak Berbasis A ktivitas. Bandung: Widya Padjadjaran.

Effendi, Rahmad. 2017. M anusia di Era Digital. Yogyakarta: Jalasutra.

Endraswara, Suwardi. 2003. M etodologi Penelitian Sastra, Epistemologi; Model Teori dan A plikasinya. Yogyakarta: Pustaka Widyatama.

Izzati, Sri. 2014. Kecil-Kecil Punya Karya: Sejuta Bibit Impian. Bandung: Mizan.

Jabrohim. 2003. M etodologi Penelitian Sastra. Yogyakarta: Hanindata Graha Widy.

Kemendikbud. 2012. Panduan Integrasi Pendidikan Karakter dalam Pembelajaran Bahasa Indonesia di Sekolah Dasar. Kemendikbud.

Kurniawan, Heru. 2013. Sastra A nak dalam Kajian Strukturalisme, Sosiologi, Semiotika, hingga Penulisan K reatif. Yogyakarta: Graha IImu.

Kurniawan, Syamsul. 2013. Pendidikan Karakter. Yogyakarta: Ar-Ruzz Media.

Nurgiyantoro, Burhan. 2013. Sastra A nak Pengantar Pemahaman Dunia A nak. Yogyakarta: Gajah Mada University Press.

Wachid, Abdul B.S. 2013. Sastra Pencerahan di Era M odern. Yogyakarta: Centra Grafindo. 
